\title{
Computer-Aided Manufacturing of a Shaft for Wood Chipper using Autodesk Inventor 2020
}

\author{
Peter Tirpak, Peter Michalik, Jozef Macej \\ Faculty of Manufacturing Technologies with a seat in Presov, Technical University of Kosice, \\ Sturova 31, 08001 Presov, Slovakia
}

\begin{abstract}
The article deals with the use of CAD / CAM software Autodesk Inventor in the production of the shaft. CAM programming is very important in the field of engineering because it speeds up the process of manufacturing parts and enables the production of their complex shapes. The article describes the programming of turning, milling, drilling and threading of the shaft. The programming was followed by the production of the shaft. The manufactured shaft met the dimensions according to the technical documentation and was subsequently used in the assembly.
\end{abstract}

Keywords - Milling, Turning, Drilling, Threading, CAD, CAM, CNC programming, CNC machining

\section{Introduction}

The shaft described in this article is part of a wood chipper which can be seen in Figure 1. This type of wood chipper is powerful, durable and reliable. The wood chipper is designed for processing garden waste as tree branches with a diameter of up to 40 $\mathrm{mm}$. Chopped waste from the garden can be used in compost, or it is possible to use the chopped wood as fuel.

DOI: $10.18421 /$ SAR42-01

https://doi.org/10.18421/SAR42-01

Corresponding author: Peter Tirpak,

Technical University of Kosice, Faculty of Manufacturing

Technologies with a seat in Presov, Sturova 31, 08001

Presov, Slovakia.

Email: peter.tirpak@tuke.sk

Received: 08 April 2021.

Revised: 11 June 2021.

Accepted: 16 June 2021.

Published: 28 June 2021.

(C) 2021 Tirpak Peter, Michalik Peter \& Jozef Macej; published by UIKTEN. This work is licensed under the CC BY-NC 4.0 licence.

The article is published with Open Access at: www.sarjournal.com
The basis of the wood chipper consists of two rotating shafts with blades. One shaft rotates opposite the other shaft. The wood waste is drawn between the rotating blades, which approach each other and separate the pieces of wood.

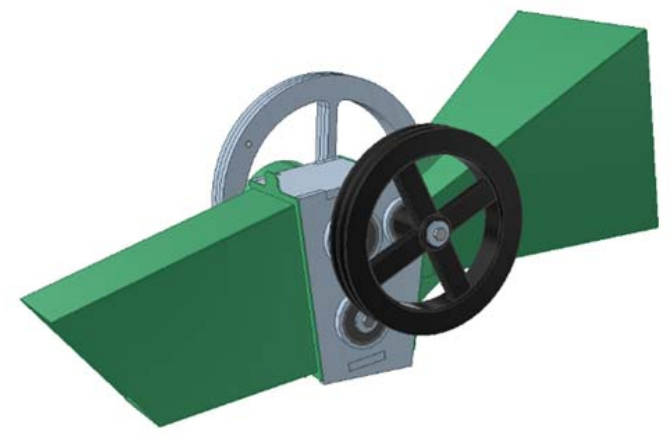

Figure 1. Wood chipper design - complete assembly

In Figure 2 we can see a detail of the rotating shafts with blades. The blades are fixed to the shaft with screws that allow adjusting the position of the blades, so that there is a minimum distance between opposing blades during wood cutting. Thanks to the screw connections, the blades can be easily removed and sharpened, or completely replaced. The wood chipper chassis and blades were made of steel plates, using a CNC plasma cutting machine.

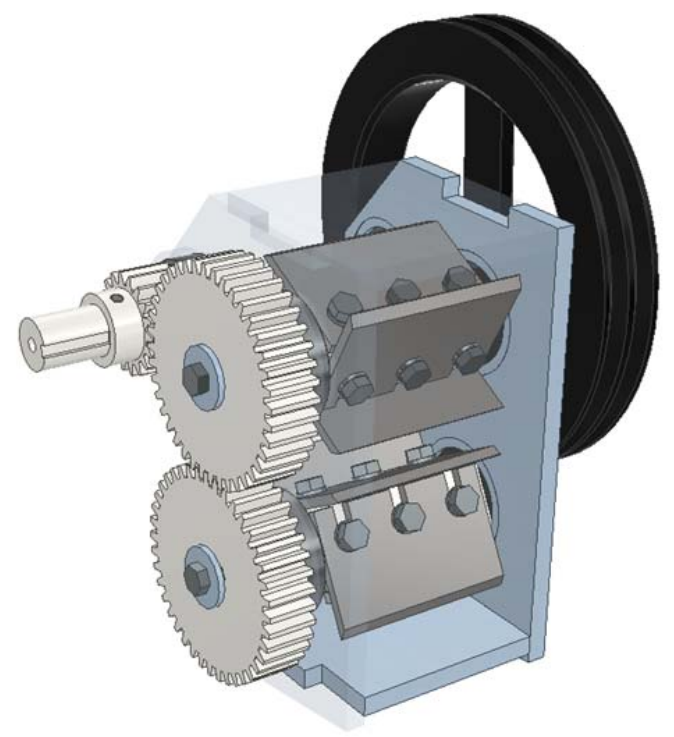

Figure 2. Wood chipper design - detail on rotating blades 
The shafts for the blades were made of a steel square bar grade S355 with dimension $35 \times 35 \times 170 \mathrm{~mm}$. The production of the shaft consisted of four production operations - turning, milling a keyway, drilling screw holes and threading. A CNC lathe and a vertical machining centre were required for the production of the shafts. CAD/CAM software Autodesk Inventor 2020 was used to program CNC machines. During production, the highest demands were placed on the precise production of shafts diameters on which bearings were pressed and a gear wheel was placed.

\section{Creating a Program for CNC Turning}

First, a 3D shaft design was created in Autodesk Inventor 2020 software. 3D modeling is the necessary stage the geometry of the part is designed in. In the modern product engineering, describing in terms of geometry of a part cannot be completely separated from taking into account the technological criteria. Quality of the outcome of the conception process is strongly influenced by the level of integration of the constructive and technological aspects of the stage of designing [1].

Figure 3 shows the design of the manufactured shaft. In the picture we can see two turned parts at the ends of a shaft with a diameter of $25 \mathrm{~mm}$ for a length of $45 \mathrm{~mm}$ and $17 \mathrm{~mm}$. Bearings will be pressed onto these parts of the shaft. The Autodesk Inventor CAM [2] module was used to create a program for a CNC lathe. The first step in programming was to define the workpiece and zero point, which are shown in Figure 4.

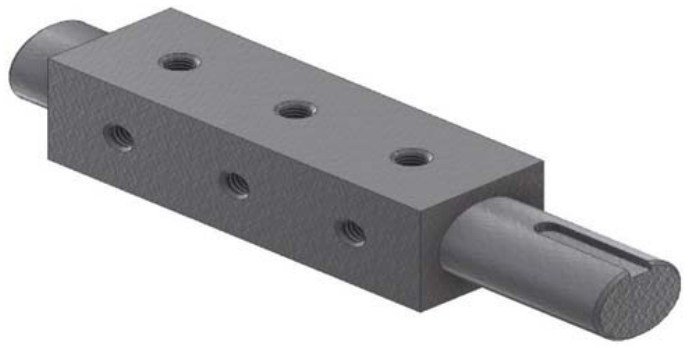

Figure 3. Shaft design in Autodesk Inventor 2020 software

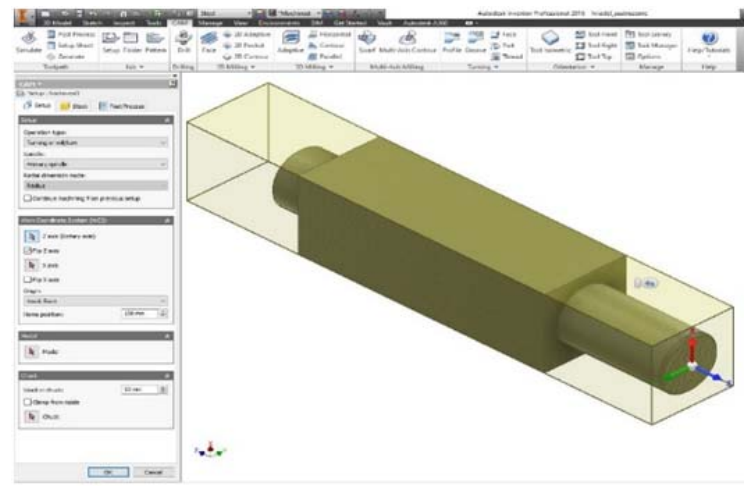

Figure 4. Autodesk Inventor CAM module - workpiece and zero point definition
Subsequently, a turning tool was selected. For the rough machining of the shaft was selected a blade turning knife from the manufacturer Sandvik Coromant, with a cutting insert type CNMG 120404PM 4425 [3]. In Figure 5 we can see the tool settings in the CAM module.

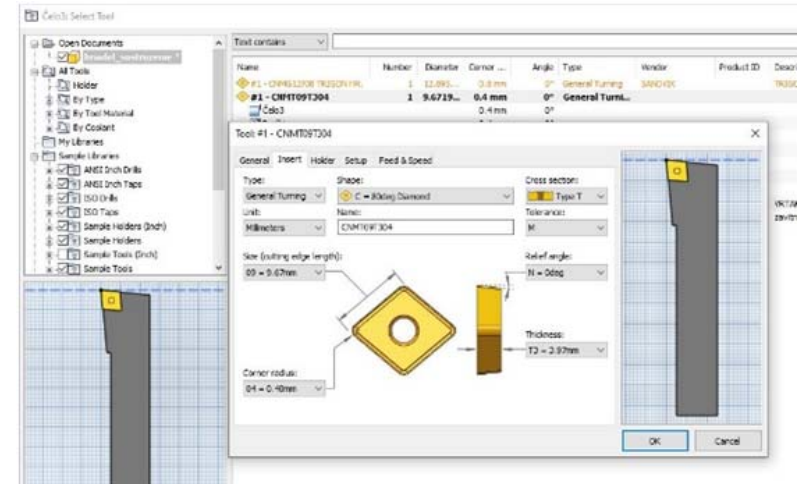

Figure 5. Autodesk Inventor CAM module - turning tool settings for roughing

After setting the turning tool, the cycle for roughing the shaft profile was selected and the machining area was defined. Figure 6 shows the parameters settings of the turning cycle. First, the shaft was roughly machined to a diameter of 25,5 $\mathrm{mm}$. The turned diameter was produced with an addition of $0,5 \mathrm{~mm}$ in diameter.

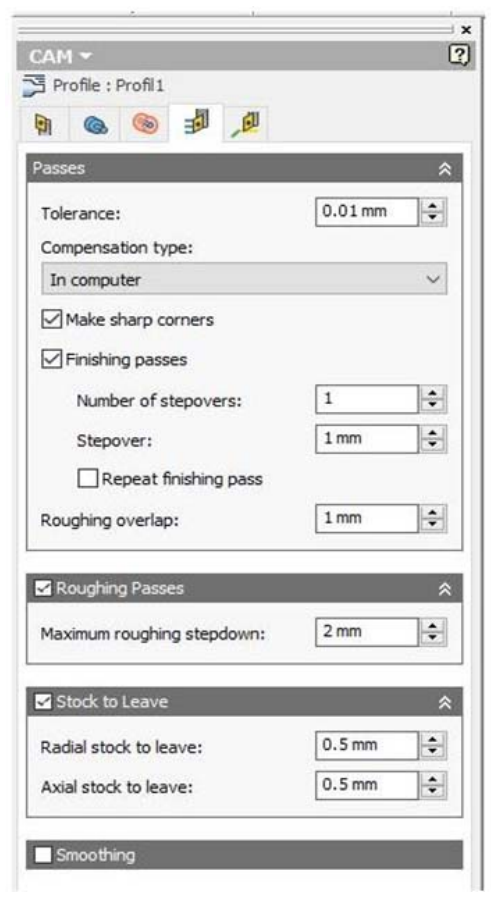

Figure 6. Autodesk Inventor CAM module - setting the profile machining cycle for roughing

During roughing, speed S of $700 \mathrm{rpm}$ and working feed F $0.10 \mathrm{~mm}$ per revolution were chosen. Lower speeds and feeds were set due to an intermittent cut when turning a square bar. Figure 7 shows the generated tool paths for rough machining to a diameter of $25,5 \mathrm{~mm}$. 


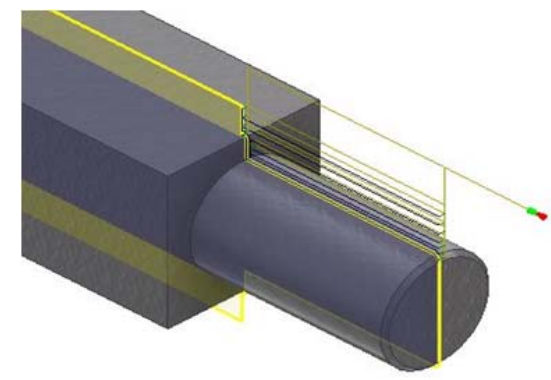

Figure 7. Autodesk Inventor CAM module - shaft roughing tool path

Roughing was followed by finishing to a final shaft diameter of $25 \mathrm{~mm}$. The tool was changed to a turning knife Sandvik Coromant with cutting insert type VNMG 160412-PM 4335 [4]. In Figure 8 we can see the definition of the parameters of the finishing tool.

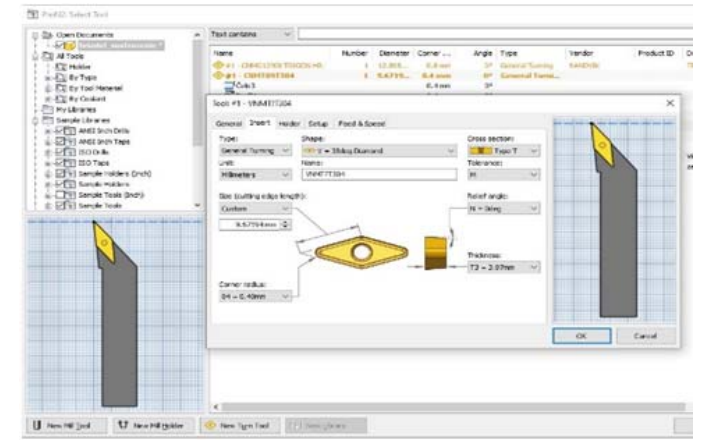

Figure 8. Autodesk Inventor CAM module - tool settings for finishing

The profile machining cycle was selected again for programming the final dimension $\varnothing 25 \times 45 \mathrm{~mm}$. The selected machining shape was the same as when roughing the diameter $25,5 \mathrm{~mm}$, but during finishing the addition of $0,5 \mathrm{~mm}$ was turned and thus the diameter $25 \mathrm{~mm}$ was achieved. The profile machining settings are shown in Figure 9. Only one toolpath was created for finishing, as one can see in Figure 10.

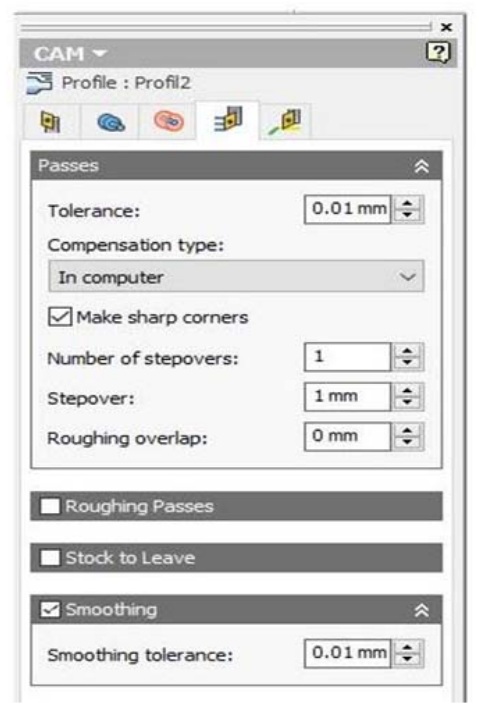

Figure 9. Autodesk Inventor CAM module - setting the profile machining cycle for finishing

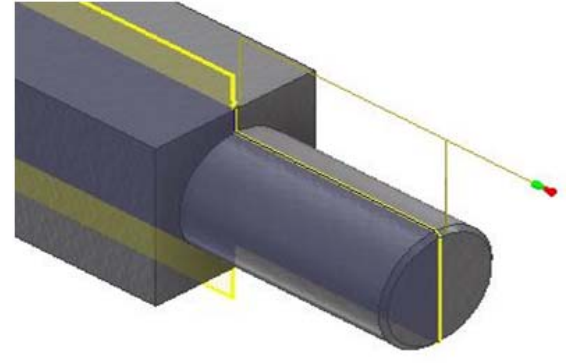

Figure 10. Autodesk Inventor CAM module - shaft finishing tool path

When finishing the shaft, speeds $\mathrm{S}$ of $1200 \mathrm{rpm}$ and working feed $\mathrm{F}$ of $0.20 \mathrm{~mm}$ per revolution were chosen. By increasing the speed and the working feed, the required roughness of the machined part of the shaft was achieved.

After the two machining cycles described in this chapter, the shaft was machined at one end to a diameter of $25 \mathrm{~mm}$ to a length of $45 \mathrm{~mm}$. Subsequently, the shaft was turned in the opposite direction and the turning was repeated from the other side. The same cycles and settings were used. Only another machining area with a length of $17 \mathrm{~mm}$ was selected.

\section{Creating a Program for Milling of a Keyway}

Turning was followed by milling of the keyway, which was used to connect the shaft to the gear wheel. The keyway was milled to a diameter of $\varnothing 25 \times 45 \mathrm{~mm}$. The width of the keyway was $6 \mathrm{~mm}$. The turned shaft was clamped in a vice on a vertical machining centre. The procedure for milling programming was the same as for turning programming using machining cycles. The first step was to define the workpiece and set the zero point to the centre of the workpiece. This setting is shown in Figure 11.

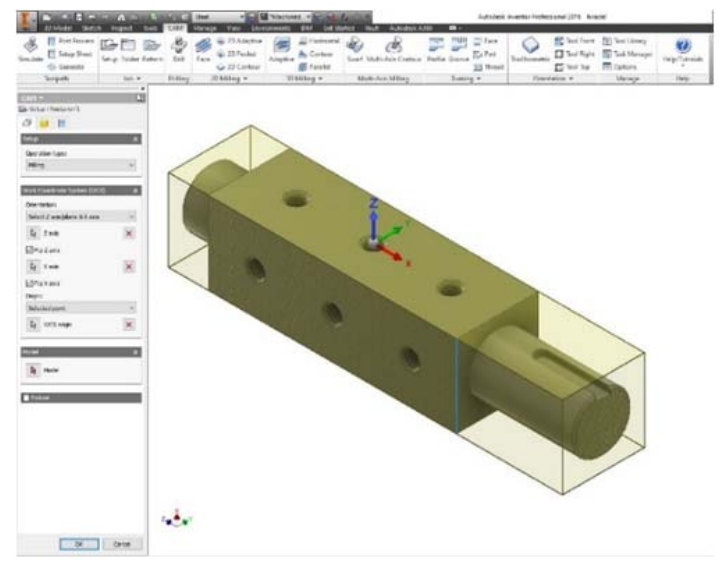

Figure 11. Autodesk Inventor CAM module workpiece and zero point definition for keyway milling

Subsequently, the tool was selected. We decided to use a double-edged grooving cutter with a diameter of $6 \mathrm{~mm}$. The selection of the milling tool is shown in Figure 12. 


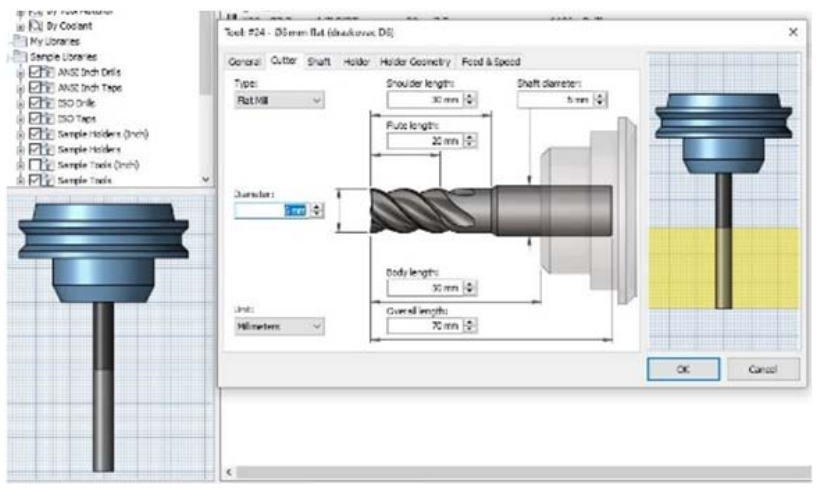

Figure 12. Autodesk Inventor CAM module - tool selection for milling

After defining the tool parameters, the machining cycle for milling was selected. The keyway was milled in layers $1 \mathrm{~mm}$ thick. Figure 13 shows the cycle setting. After setting up the milling cycle and setting up the milling tool, the CAM module in Autodesk Inventor generated paths for milling the keyway. These toolpaths are shown in Figure 14.

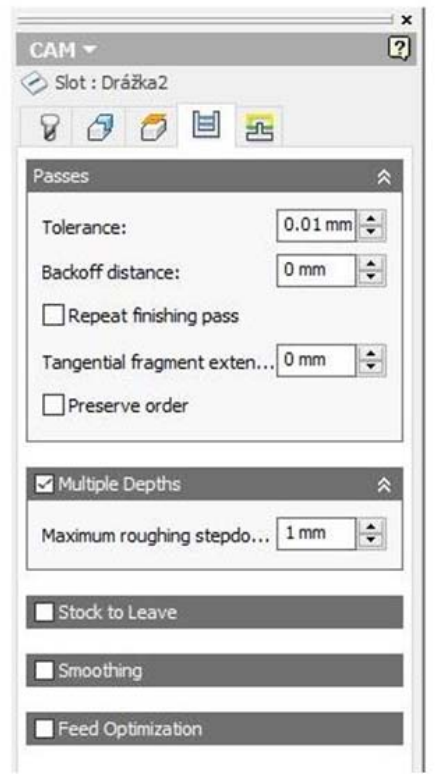

Figure 13. Autodesk Inventor CAM module - milling cycle setting

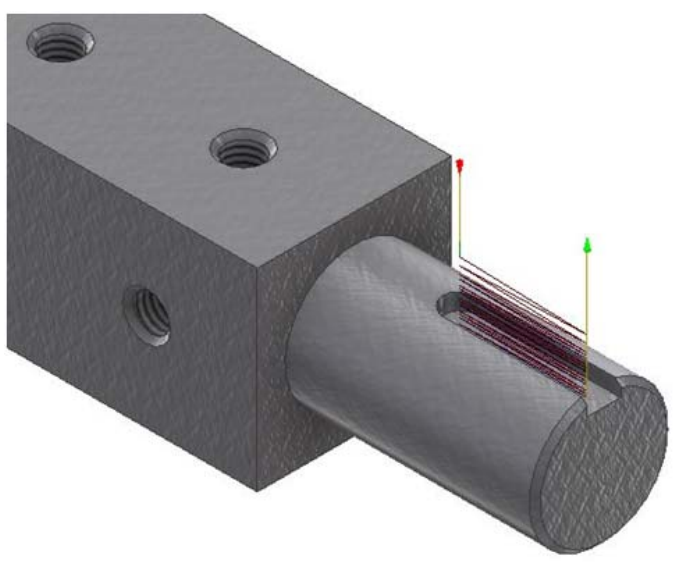

Figure 14. Autodesk Inventor CAM module - toolpaths for milling the keyway

\section{Creating a Program for Drilling and Threading}

At the end of the production of the shaft, it was necessary to make six holes through the entire shaft with an M8x1.25 thread. The production of threaded holes consisted of three steps:

- $\quad$ spot drilling

- drilling

- threading

We first created spot drills to guide the drill. Spot drills were also used to chamfer the edge of the hole before threading. We chose a spot drill with a diameter of $16 \mathrm{~mm}$ and its settings and parameters are shown in Figure 15. After this setting, the drilling cycle was selected and points for spot drilling were marked. The drilling depth was set to $1 \mathrm{~mm}$.

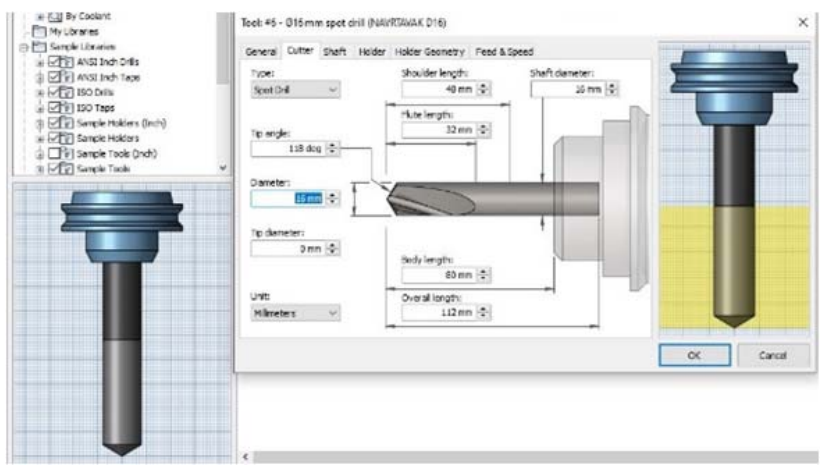

Figure 15. Autodesk Inventor CAM module - tool selection for spot drilling

This was followed by drilling holes with a diameter of $7,7 \mathrm{~mm}$. The drilling was to a depth of $38 \mathrm{~mm}$ so that the hole was drilled through the entire shaft. A carbide drill with internal cooling was used as a tool. Its parameters are shown in Figure 16.

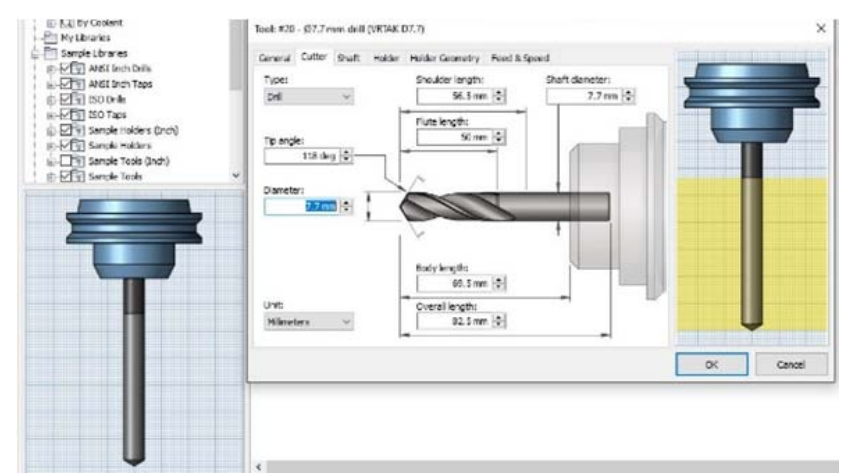

Figure 16. Autodesk Inventor CAM module - tool selection for drilling

After drilling the first three holes through the entire shaft, a program stop followed. The shaft was shifted $90^{\circ}$ in the vice and the same drilling cycles were used again to drill three more holes.

After drilling the tap holes, threading followed as the last operation. An M8x1,25 machine tap was used 
for threading. Figure 15 shows the parameters of the threading tool. The thread cycle was selected and the holes for threading were marked. The threading depth was $17,5 \mathrm{~mm}$. This depth has been defined so that the tap is not destroyed during threading. Threading was similar to drilling, but the shaft was rotated $90^{\circ}$ in the vice four times. After each rotation of the shaft, three threads were made. Figure 18 shows the toolpaths for drilling and threading a manufactured shaft.

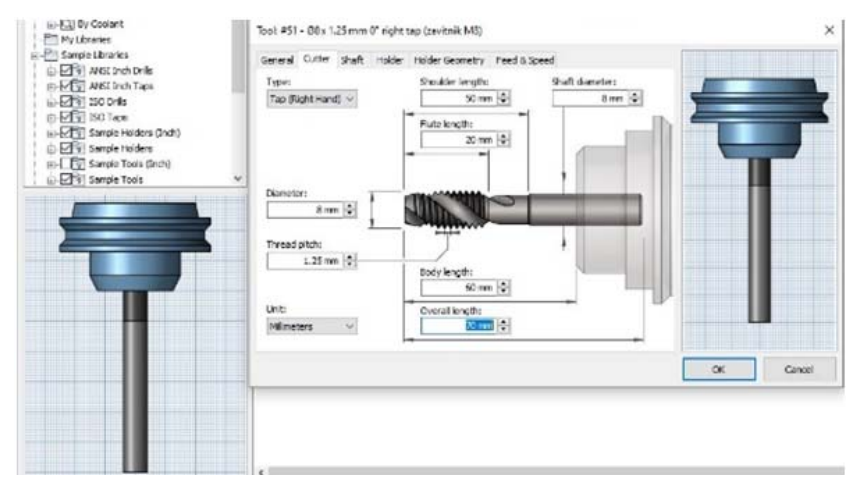

Figure 17. Autodesk Inventor CAM module -tool selection, metric machine tap M8x1,25

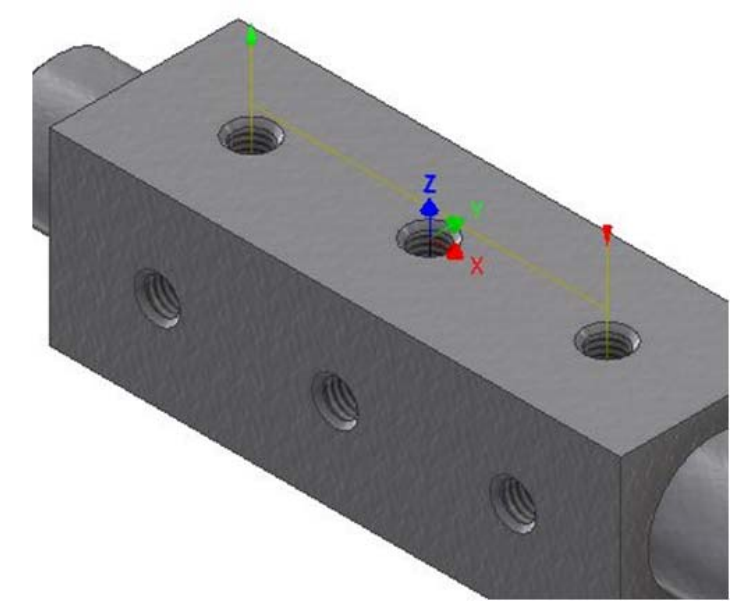

Figure 18. Autodesk Inventor CAM module - drilling and threading toolpaths

\section{Shaft Production}

A semi-finished product in the shape of a square bar with dimensions of $35 \times 35 \times 170 \mathrm{~mm}$ made of steel grade S355 was turned on a CNC lathe Viper VT28BL-1500. Based on the program that we created using the CAM module, we first machined the shaft ends to the required diameter of $25 \mathrm{~mm}$. After turning, the shaft was clamped in a vice on a Pinnacle 1700 s vertical machining centre, on which a keyway was milled and threaded holes were made. After finishing on the machining centre, an additional deburring of the shaft followed. The dimensions of the shaft were measured with a calliper. All dimensions were adhered to according to the production documentation. The shaft has been released for mounting. Figure 19 shows the finished shaft.

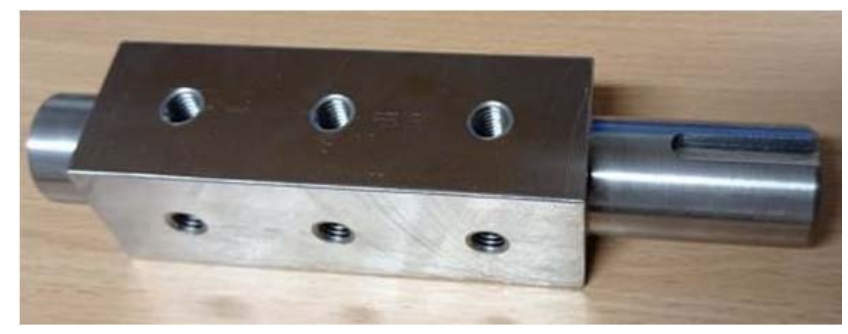

Figure 19. Shaft after production

\section{Conclusion}

In this article, we have tried to show the benefits of computer aided design and computer aided manufacturing. Thanks to Autodesk Inventor 2020, we were able to design a complete wood chipper. We have successfully used the CAM module to generate programs for the $\mathrm{CNC}$ lathe and $\mathrm{CNC}$ vertical machining center needed to manufacture the parts. The shaft whose production we have described in this article fully complies with the project documentation.

\section{References}

[1]. Drăgoi, M. V. (2010). Advances in CAD/CAM Technologies. New Trends in Technologies: Devices, Computer, Communication and Industrial Systems, 67. DOI: $10.5772 / 10441$.

[2]. Inventor CAM - Integrated CAM software for Inventor simplifies CNC programming processes. Retrieved from:

https://www.autodesk.com/products/inventorcam/overview?plc $=$ PDCOLL\&term $=1$ YEAR\&support=ADVANCED\&quantity $=1$, [accessed: 22 February 2021].

[3]. Sandvik Coromant metal cutting tools (a). Retrieved from:

https://www.sandvik.coromant.com/en$\mathrm{gb} /$ products/pages/productdetails.aspx? $\mathrm{c}=\mathrm{CNMG} \% 20$ 12\%2004\%2004-PM\%20\%20\%20\%204425, [accessed: 22 February 2021].

[4]. Sandvik Coromant metal cutting tools (b), Retrieved from:

https://www.sandvik.coromant.com/en$\mathrm{gb} /$ products/Pages/productdetails.aspx? $\mathrm{c}=\mathrm{VNMG} \% 20$ 16\%2004\%2012-PM\%20\%20\%20\%204335 [accessed: 25 February 2021]. 